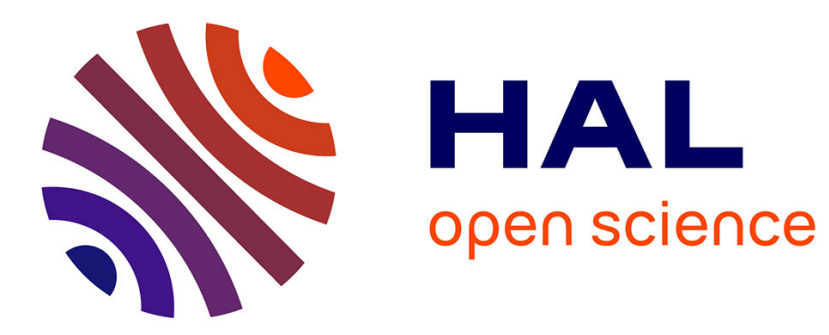

\title{
SPFC: a tool to improve water management and hay production in the Crau region
}

\author{
J.C. Mailhol, A. Merot
}

\section{To cite this version:}

J.C. Mailhol, A. Merot. SPFC: a tool to improve water management and hay production in the Crau region. Irrigation Science, 2008, 26 (4), p. 289 - p. 302. 10.1007/s00271-007-0099-3 . hal-00453853

\section{HAL Id: hal-00453853 \\ https://hal.science/hal-00453853}

Submitted on 5 Feb 2010

HAL is a multi-disciplinary open access archive for the deposit and dissemination of scientific research documents, whether they are published or not. The documents may come from teaching and research institutions in France or abroad, or from public or private research centers.
L'archive ouverte pluridisciplinaire HAL, est destinée au dépôt et à la diffusion de documents scientifiques de niveau recherche, publiés ou non, émanant des établissements d'enseignement et de recherche français ou étrangers, des laboratoires publics ou privés. 


\author{
Jean Claude Mailhol ${ }^{1}$ and Anne Merot ${ }^{2}$ \\ Under press in Irig. Sci
}

\begin{abstract}
This article deals with the development and application of SPFC, a model used to improve water and grassland production (HC) in this region of France. This model is composed of two sub-models: an irrigation model and a crop model. As the fields are border irrigated, these two sub-models are coupled. The crop model simulates dry matter, Leaf Area Index (LAI) and soil water reserve (SWR) variations. LAI and SWR are both used for border model updating: SWR for the deficit of saturation required by the infiltration equation and LAI for the roughness coefficient $n$. After calibration and validation, SPFC is then used to identify realistic management strategies for the irrigation and production system at the plot level. By scheduling irrigation when SWR is 50\% depleted, would result in a low Dry Matter DM production loss (around 10\%), reduced labour (8 irrigation events instead of 11) and in significant water saving compared with farmers' practices, on the basis of an average climatic scenario. Furthermore, this improvement of irrigation efficiency is not incompatible with groundwater recharge used for the potable water supply of the region.
\end{abstract}

Key words

Border irrigation, grasslands, Water balance, irrigation model, crop model, coupling models

\title{
Introduction
}

In the Crau region (in the Southern France), the primary ecosystem is a semi-arid steppe with a high climatic water deficit from April to August and no natural rivers (Boutin and Cheylan, 2004). Water transfers from the Alpes through the Durance River allow the development of multi-specific and permanent grasslands which are the basis of local agriculture. These grasslands, which are sensitive to water stress (Merot et al., 2007), are used for hay production: 'Crau hay' labelled to be of Certified Origin Product (COP).

They are irrigated using the border system on soils having a water retention capacity that is significantly reduced by the presence of boulders which enhances the soil macro-pore effect on infiltration. Under such soil conditions, the cut-off time required to irrigate an average plot length of $450 \mathrm{~m}$ can be greater than $8 \mathrm{~h}$. Even if water is cut-off before reaching plot end, in order to limit runoff losses, a great water amount (close to $60 \%$ of the water applied) is lost through percolation which recharges the superficial groundwater. The latter strongly reacts to irrigation. Its level can fluctuate from $6 \mathrm{~m}$ (at the beginning of the irrigation season) to a $1.4 \mathrm{~m}$ depth just after an irrigation event according to Saos et al., (2006). It ensures the potable water supply of nearly two hundred thousand people. Moreover, the

\footnotetext{
${ }^{1}$ UMR G-EAU (CEMAGREF-ENGREF-CIRAD-IRD), Cemagref - 361, rue J.F. Breton - BP 5095 - F34033 Montpellier - France.

${ }^{2}$ UMR System (Agro.M-CIRAD-Inra) - bâtiment 27 - 2 Place Viala - 34060 Montpellier Cedex 2 - France.
} 
groundwater recharge and the water that flows in the numerous open earth channels (some of them receive tail-water runoff from plots) contribute to the ecosystem equilibrium.

The Crau region is generously supplied by the Durance river from the Serre Ponçon $\operatorname{dam}\left(30 \mathrm{~m}^{3} \cdot \mathrm{s}^{-1}\right.$ of water rights for an irrigated area approaching $\left.33000 \mathrm{ha}\right)$ and, consequently, water saving is not a priority yet. Nevertheless, the share of the Durance's flow is currently under discussion following the acknowledgement of new water user rights and to better take into account the ecological context of the river (Balland, 2002). Farmers are thus encouraged to limit their water consumption. In the present context, according to an average farmer's practice, a field is irrigated 15 times on average with a water application close to 24000 $\mathrm{m}^{3} / \mathrm{ha}$, and a hay yield ranging from 8 to $10 \mathrm{~T} / \mathrm{ha}$. Replacing surface by sprinkler irrigation would eliminate the beneficial role played by surface irrigation in groundwater recharge and ecosystem preservation. Moreover, such a project is not conceivable for most of the farmers both from an economical and technical point of view (extreme windy conditions). In addition to water savings, farmers are also confronted with a labour issue: irrigation is very timeconsuming. During a half-year, 24h/24h (plots are often also irrigated at night), farmers have to distribute water to every field on the farm. Thus, a question that often arises is how Crau Hay production could be improved, through water and labour saving, without a fundamental modification of the cropping system?

In this article, our objective is to present the development of a model that can be used to test the impact of a decision rule on the hay production at the plot scale and for a given climatic scenario. These decision rules can refer to the irrigation (irrigation scheduling, irrigation timing, discharge and cut-off time, and plot sizes) and mowing management.

The development of two types of models is proposed in this work. An irrigation model, that estimates the water application depth profile for an irrigation event, and a crop model, that predicts the water balance and the hay yield for the whole season. Due to their inter-dependence (outputs of one's being inputs of the other and vice versa), these two models have to be coupled. In future works, this coupled model will be integrated in a Decision support system (DSS) composed entirely of decision rules among which the water allocation priority or the mowing management of the different plots, will constitute the basis of the model used for water management and hay production at farm level.

\section{Material and methods}

\section{Modelling approach}

The modelling approach possesses three distinct modelling elements (Fig.1). The first element is SIP, a hydraulic model that predicts the advance infiltration process. It calculates the water application depths (WAD), which are inputs of virtual elementary sub-plots constituting the field. The soil properties of the field are assumed to be spatially constant. The sub-plot concept has been adopted to take into account the heterogeneity of WAD profile along the field. SIP requires parameters (LAI: Leaf Area Index, $\theta_{0}$ : initial soil water content) which are updated before each irrigation events by the crop model PILFC, the second modelling element. These two models are interconnected by a decision model which is the third element. The latter permits the application of decision rules regarding irrigation. Farmer practices (irrigation dates, cut-off time strategies, inlet discharge) or irrigation scheduling associated to the choice of an adapted Q- $t_{\text {co }}$ couple can be tested. The two main elements of this modelling approach are now presented, followed by field experiments used for model calibration and evaluation. 
SIP: a border irrigation model for the prediction of a water application depth WAD profile.

With regards to hydraulic surface modelling processes in border irrigation, progress in terms of accuracy has stagnated since the end of the 90's after the published manual of Strelkof et al., (1996). The authors deal with different irrigation practices such as the no tailwater runoff practice (blocked-end border), and the zero-inertia solution (the first simplification of the complete St Venant equation) is also proposed in this manual. Nevertheless, the infiltration model based on the empirical Kostiakov (1932) equation does not allow soil conditions to be taken into account. The software package proposed by Walker (2003) for the SIRMOD model that can be used for both border and furrow systems, also has the same drawback. Recently, Zatarian et al. (2003), have improved the predictive character of infiltration by using the Green et Ampt (1911) equation. But, the strong hypothesis attached to this infiltration model (Philip, (1973)) is not compatible with the Crau soil context where infiltration is dominated by macro pore effects (Mailhol, 2003). This remark is also valid for the Saucedo et al., (2005) model combining the St Venant equations with the Richards (1931) infiltration model, the whole resulting in a cumbersome tool due to its high number of parameters.

The border model we use in this study is based on the kinematic wave equations (Walker and Humpherys, 1983):

$$
\frac{\partial A}{\partial t}+\frac{\partial Q}{\partial x}=-q(\tau)
$$

, the mass conservation equation of the St Venant model associated to:

$\mathrm{S}_{0}=\mathrm{S}_{\mathrm{f}}=\mathrm{n}^{2} \mathrm{Q}^{2} /\left(\mathrm{A}^{2} \mathrm{R}^{4 / 3}\right)$

, for the surface flow, where $A=$ cross section flow, $\mathrm{Q}=$ discharge, $\mathrm{t}=$ current time, $\mathrm{q}$ infiltration rate, $\tau=$ opportunity time, $\mathrm{S}_{0}=$ slope of the border, $\mathrm{S}_{\mathrm{f}}=$ friction slope, $\mathrm{n}=$ roughness coefficient, $\mathrm{R}=$ hydraulic radius. The border slope range $\left(0.2 \%<\mathrm{S}_{0}<0.3 \%\right)$ and the tail-water runoff practice used in the Crau region reinforces our choice of this St Venant solution which uses a Newton-Raphson solution more numerically stable than the other St Venant solutions.

The numerical solution of $\mathrm{Eq}(1)$ is obtained using a first-order Eulerian integration. The numerical solution of the equation of the two equations is based on the moving deformable cell method resulting in a computational net in the $x-t$ plane. The latter is composed of oblique cells that favour accurate numerical solutions. This numerical scheme was developed by Strelkov and Katapodes (1977) and has been widely used by many other specialists of surface irrigation (Walker and Humpherys, 1983; Rayej 1985; Walker, 1999; Walker 2003).

The Kinematic-Wave Model (KWM) does not consider the depletion phase, but according to Walker and Humpherys, (1983), an artificial depletion phase can be added. In SIP, depletion is calculated using the formulation proposed by Walker (2003) in his guideline on SIRMOD III (page 76). This formulation allows the estimation of the depletion phase duration (DPD), while taking into account inlet discharge Qin, $\mathrm{n}, \mathrm{S}_{0}$, stabilised infiltration rate, and furrow length. This DPD is added, with respects to a spatial distribution, on the recession phase simulated by KWM. It is assumed to exponentially decrease from DPD at $\mathrm{x}=$ 0 to 0 at $\mathrm{x}=\mathrm{x}_{\mathrm{d}}$, in relation to an acceptable mass conservation criterion. The latter reaches around 2.5\% when DPD is not taken into consideration and $1.5 \%$ or less when DPD is added.

The subsurface flow is governed by the predictive form of Horton's infiltration equation (Mailhol, 2003; Mailhol et al., 2005). 
$\mathrm{I}(\tau)=\lambda \mathrm{c} \Delta \theta\left[1-\exp \left(\chi \mathrm{Ks}(\lambda \mathrm{c} \Delta \theta)^{-1} \tau\right)\right]+\mathrm{Ks} \tau$

, with $I(\tau)=\int_{0}^{\tau} q(t) d t$, and where $\lambda \mathrm{c}=$ capillary length, $\Delta \theta=\theta \mathrm{s}-\theta \mathrm{i}$, Ks $=$ saturated

conductivity and $\chi$ an empirical parameter governing the macro-pore effect at the early stage of infiltration. The greater the $\chi$ the faster water fills macroporous spaces. The significance of macro-porosity is, in addition, directly linked to the linear character of the front advance trajectory (Mailhol and Gonzalez, 1993; Mailhol et al. 1999). It is worthwhile to take into account the predictive character of the infiltration equation via the saturation deficit $\Delta \theta$ which impacts on the advance process, as shown below.

\section{PILFC: a daily time-step model to simulate water balance and Hay Crau (HC) production}

When dealing with the problem of multi-specific grassland growth, a model based on the morphogenetic processes (Calvière et Duru, 1995; Corson et al., 2006) is not easy to apply, due to the inter-dependence of the different species. Instead of considering groups of species, each one having its unique functioning process, grassland is considered as a unique crop; and to take into consideration the coupling of two models, a general approach is adopted. Because of the lack of models available to simulate the multi-species evolution of grassland under the climatic conditions of the Crau region, PILFC, an operative modelling approach is adopted, which is partially based on the PILOTE model (Mailhol et al., 1997, Mailhol et al. 2004). The environmental aspect linked to nitrogen leaching is not considered in this study because water transfer through the soil-plant system plays the major role in this modelling approach.

PILFC brings together a soil module and a plant module respectively to simulate the water balance and the HC herbage growth.

The soil module of PILFC:

The PILFC soil module provides water balance and water stress index (WSI) estimations. It requires daily climatic data such as precipitation $\mathrm{P}$, reference evapotranspiration, $\mathrm{ET}_{0}$, solar radiation $\mathrm{S}$ and average temperature $\mathrm{T}$. It is composed of three reservoirs $\left(\mathrm{R}_{1}, \mathrm{R}_{2}\right.$ and $\left.\mathrm{R}_{3}\right)$ in order to account for different soil water transfer processes and soil variability with depth. As in the PILOTE model (Mailhol et al., 1997; Mailhol et al., 2004), a shallow reservoir $R_{1}$ having a depth $Z_{1}$ set to $0.1 \mathrm{~m}$, governs flux exchanges with the atmosphere. The depths of $R_{2}$ and $R_{3}$ are governed by the variability of the soil properties, the cumulative depths $\mathrm{Zr}=\mathrm{Z}_{1}+\mathrm{Z}_{2}+\mathrm{Z}_{3}$ equating the maximal root depth of the plant system. The only difference between the PILFC and PILOTE soil modules is in the transfer processes involving the two subsequent reservoirs. The PILOTE soil module, unlike this one, has a soil water reserve varying with root depth.

Soil evaporation Es, is assumed to be only provided by the shallow reservoir $R_{1}$ according to:

$\mathrm{Es}=(1-\mathrm{Cp}) \mathrm{ET}_{0}$

,where $\mathrm{Cp}$ is the partitioning coefficient linked to the leaf area index (LAI ). It is used to calculate potential transpiration $\mathrm{Tp}=\mathrm{Cp}$.MET with maximal evapotranspiration $\mathrm{MET}=$ $\mathrm{Kc}_{\mathrm{ET}}$, Kc being the crop coefficient.,

For as long as possible, water is captured in this reservoir, that is supplied by rainfall and irrigation. It then drains $\left(\mathrm{d}_{1}\right)$ into a second one when the soil water content exceeds the threshold value $\mathrm{R}_{1} \sup =\left(\theta_{\mathrm{Fc} 1}-\theta_{\min 1}\right) \mathrm{Z}_{1}$. The water balance corresponding to this first reservoir is given by: 
$\mathrm{R}_{1}(\mathrm{j})=\mathrm{R}_{1}(\mathrm{j}-1)+\mathrm{P}(\mathrm{j})+\operatorname{Irrig}(\mathrm{j})-\mathrm{Tp}(\mathrm{j})-\mathrm{Es}(\mathrm{j})-\mathrm{d}_{1}$

,With $\mathrm{d}_{1}=\max \left\{\left[\mathrm{R}_{1} \sup -\mathrm{R}_{1}(\mathrm{t})\right] ; 0\right\}$, the amount of water percolated from $\mathrm{R}_{1}$ at the end of the day $\mathrm{j}$. When $\mathrm{R}_{1}$ can partially supply the water demand then:

$\operatorname{Es}(\mathrm{j})=(1-\mathrm{Cp})\left[\mathrm{R}_{1}(\mathrm{j}-1)+\mathrm{P}(\mathrm{j})\right]$

$\mathrm{Tp}_{1}(\mathrm{j})=\mathrm{Cp}\left[\mathrm{R}_{1}(\mathrm{j}-1)+\mathrm{P}(\mathrm{j})\right]$

, and the lack: $\left(-R_{1}(j)\right)$ to satisfy the water demand, is taken from the second or the third reservoir, partially or totally, depending of their respective water contents.

When $R_{1}$ is empty at the beginning of the time step: MET is taken from the subsequent reservoirs $\left(\mathrm{R}_{2}\right.$ and/or $\left.\mathrm{R}_{3}\right)$ based on the principle that plants try to transpire at the maximal rate (i.e. at MET).

Plant water uptake rate in a reservoir $R_{i}(i>1)$ depends on its water content level. As long as there is water in the easily usable water reserve defined by $R_{\mathrm{iEu}}=\mathrm{Kr}$. $\left(\theta_{\mathrm{Fci}}-\theta_{\text {mini }}\right) Z_{\mathrm{i}}$ the reservoir can supply water at the MET rate, $\mathrm{Kr}$ being the Doorenbos and Kassam (1979) coefficient. When water is taken up from the surviving reserve: $\operatorname{Rs}_{\mathrm{i}}=(1-\mathrm{Kr})\left(\theta_{\mathrm{Fci}} \cdot \theta_{\text {mini }}\right) \mathrm{Z}_{\mathrm{i}}$ actual transpiration linearly decreases according to :

$\mathrm{ATp}_{\mathrm{i}}=\operatorname{Min}\left\{1 . ; \mathrm{R}_{\mathrm{i}} / \mathrm{Rs}_{\mathrm{i}}\right) \mathrm{MET}$

When $\mathrm{R}_{2}$ cannot supply this rate, the part of MET (or the totality) not satisfied, is taken, when possible, in $\mathrm{R}_{3 \mathrm{Eu}}$. When MET can only be partially provided by $\mathrm{R}_{2}\left(\mathrm{i} . \mathrm{e} .: \mathrm{Max}\left\{0 ., \mathrm{R}_{2}(\mathrm{j}-1)\right\}\right.$ ) and when $R_{3}$ cannot provide the rest $=-R_{2 E u}$, the latter is taken with the linear reduction in $R_{2}$. In this case:

$$
\mathrm{ATp}_{2}=\mathrm{R}_{2}(\mathrm{j}-1)+\mathrm{R}_{2 \mathrm{Eu}} \mathrm{R}_{2} / \mathrm{Rs}_{2}
$$

Depending on their soil water status the contribution of the different reservoirs in the total AET is: TAET $=$ Es $+T_{1}+A T p_{2}+A T p_{3}$. Of course $d_{1}$ supplies $R_{2}$ and $d_{2} R_{3}$ if their water content exceeds their field capacity, when $d_{3}$ is considered as deep percolation or drainage loss.

The plant module of PILFC:

As in PILOTE model, crop production is based on the LAI simulation obtained from Eq (10) in which RGSI, a stress index regarding the lack of radiation, has been introduced to account for the radiation impact on $\mathrm{HC}$ production:

$$
L A I(j)=L A I_{\max }\left[\left(\frac{\sum_{k=1}^{j} T T(j)}{t_{m}}\right)^{\beta} \exp \left\{\frac{\beta}{\alpha}\left(1-\left(\frac{\sum_{k=1}^{j} T T(j)}{t_{m}}\right)^{\alpha}\right)\right\} R G S I-\left(1-W S I^{\lambda}\right)\right]+\mathrm{LAI}_{0}
$$

, where $T T(j)=\sum_{1}^{j}(T(k)$, is the cumulative daily average temperature from the simulation starting, at the end of winter or from each mowing. Maximal LAI value $\mathrm{LAI}_{\max }$, is reached at the cumulative temperature $t_{\mathrm{m}}$, these two parameters are obtained by measurements. The initial $\mathrm{LAI}$ value, $\mathrm{LAI}_{0}$, is either the value at the end of winter or that observed after each grass mowing. Under those circumstances, the initial LAI value equals the minimal LAI, which is defined as $\mathrm{LAI}_{\min }$. The shape factors $\alpha$ and $\beta$ are empirical parameters calibrated by the automatic method of Rosenbrock (1960)) on a full irrigated treatment. As explained in Mailhol et al., (1997), $\alpha$ takes two values, $\alpha_{1}$ when $t_{m}>$ TT(j) and $\alpha_{2}$ when TT(j) $>t_{m}$. The water stress index, WSI, accounts for a soil water deficit on grass production (Mailhol et al., 1997.). The $\lambda$ parameter attests to plant sensitivity to water stress. The RGSI index is 
calculated according to $\mathrm{RGSI}=\min \left\{1\right.$. $\left.\sum_{k=j-10}^{k=j} \frac{S(k)}{S_{o p t}}\right\}$, where $\mathrm{S}_{\mathrm{opt}}$ is a daily radiation value under which LAI, can be affected.

From LAI, Cp can be obtained:

$\mathrm{Cp}=1-\exp (-0.65 \mathrm{LAI})$

, according to Novak (1981) and Kc:

$\mathrm{Kc}=\mathrm{K}_{\mathrm{cx}}[1-\exp (-\mathrm{LAI})]$

according to Alisson et al., (1993).

The dry matter calculation principle, although based on concepts similar to those of PILOTE, is significantly different. The dry matter accumulation, Ya at a daily time step, is calculated by:

$Y a(j)=Y a(j-1)+R p(j) R U E m ~ S(j) I(j)$

, where RUEm is the mean radiation use efficiency $\left(\mathrm{g} \cdot \mathrm{MJ}^{-1}\right) \mathrm{S}(\mathrm{j})$ the daily incident solar radiation $\left(\mathrm{J} \mathrm{m}^{-2}\right), \mathrm{I}(\mathrm{j})$ the fraction of intercepted radiation (Moussi and Sacki, 1953):

I (j) $=1-\exp \left(-k \cdot \operatorname{LAI}^{*}(\mathrm{j})\right)$,

using an extinction coefficient $\mathrm{k}=\min \left(1.0,1.43 \mathrm{LAI}^{*}{ }^{-0.5}\right)$, where $\mathrm{LAI}^{*}$, is the LAI value calculated with no stress. But in this model version, $\mathrm{Rp}(\mathrm{j})=\mathrm{CLAI} / \mathrm{CLAI}{ }^{*}$, which is the ratio between two cumulative leaf area index values on 3 days preceding the $\mathrm{j}$ day. This formulation differs from that of PILOTE (Mailhol et al., 1997) where this ratio is calculated within a critical period defined by two temperature threshold allowing the correction of the cumulative potential dry matter between sowing and maturity by Rp. Unlike PILOTE, PILFC simulates actual DM variation during the course of the season.

In the PILFC model, dry matter accumulation starts at the beginning of February where temperatures are often near zero degrees Celsius. Thus, the start of LAI coincides with that of dry matter accumulation. The latter stops when cumulative temperature TT(j) reaches a threshold value Tmat, corresponding to the end of flowering, or when mowing occurs before growth reaches the production plateau. This parameter Tmat, which corresponds to maturity, is not much higher than $t_{m}$ unlike for crops such as corn or wheat for instance.

At this point, two factors specific to local conditions have to be taken into account to model HC production. The first factor is governed by peculiar climatic conditions occurring when high temperatures are associated with significant windy conditions (Allen et al., 1998). As the radiation use efficiency RUE is affected, these conditions can reduce the HC production from 10 to $15 \%$ according to expert advice (Comité du foin de Crau, 2005, personal communication). Such conditions result in very high $\mathrm{ET}_{0}$ rates. To account for the role played by the conditions previously described it is preferable to limit the number of parameters and climatic data (wind speed for instance), consequently a relationship involving $\mathrm{ET}_{0}$ is used. According to the climatic series, $\mathrm{ET}_{0}$ values greater than a given threshold $\mathrm{EXT}_{0}$ correspond both to high temperatures and to extreme windy conditions. A second parameter, $\xi$, is used in the relationship allowing strong windy conditions to impact more or less on RUEm. 
The second factor is related to HC specificity: a grassland system composed of different species. Each species presents a different physiological growth cycle, strategy and persistence in Crau Hay composition during the course of the season. But, in grassland, the significant decline in the proportion of productive and fast-growing species, from first to last mowing, is a commonly observed phenomenon. This seasonal effect impacts the yield of the last mowing which is systematically lower than for the previous ones. Due to the difficulty involved in developing a modelling approach that allows for the prediction of the complex natural evolution of species, an empirical model based on a threshold of cumulative temperature over which the radiation use efficiency decreases, is adopted. Under average climatic conditions, this temperature threshold, $\mathrm{T}_{\mathrm{ds}}$, should roughly correspond to the beginning of the last production (generally a few days after the second mowing). An empirical parameter $\varsigma$ is involved in a classical exponential expression usually devoted to predicting the reduction of productivity of some species:

$\operatorname{Corm}(j)=\min \left[1 ., \exp \left(-\varsigma\left(S T(j)-T_{d s}\right)\right]\right.$

, where $S T(j)$ is the cumulative temperature from DOY $=1$ to the $j$ date. Note that a similar correction is applied to LAI.

When $\mathrm{LAI}_{0}$ is greater than $\mathrm{LAI}_{\min }, \mathrm{Y}_{0}$ is derived from a LAI and yield relationship calibrated within a LAI range such as $0<\mathrm{LAI}<3$ :

$\mathrm{Y}_{0}=0.6 \max \left[0 ;\left(\mathrm{LAI}_{0}-\mathrm{LAI}_{\mathrm{min}}\right)\right]^{0.8}$

Finally, the DM yield evolution for a mowing is given by:

$Y(j)=Y(j-1)+\operatorname{Corm}(j) \cdot R U E m \cdot m i n\left(1 ., E X T_{0} / E_{0}\right)^{\xi} S(j) R p(j) I(j)$

,with $\mathrm{Y}(0)=. \mathrm{Y}_{0}$ for the first mowing.

The experimental field context

Experiments were carried out over 3 years (2004 - 2006) during the growing period in two typical multi-specific and permanent grasslands (Field A and field B). The experimental field setup is presented in Fig.2. It is located in the Crau plain under a windy Mediterranean climate. The soil of the two fields is a calcic luvisol (FAO, 1981) with an irragric upper horizon (5\% stones), over an intermediate layer of loamy sand (from $15 \%$ to $75 \%$ rocks) and a petrocalcaric horizon. The upper layer is 0.1 to $0.4 \mathrm{~m}$ thick and the pudding stone is at a depth of 0.5 to $0.7 \mathrm{~m}$. Roots are concentrated in the upper $0.3 \mathrm{~m}$ and root density decreases rapidly until the pudding stone which is water permeable but does not allow root growth.

These two grasslands were divided into two irrigation borders $\left(A_{1}\right.$ and $A_{2}-B_{1}$ and $\left.B_{2}\right)$ equipped with five measurement stations installed from upstream to downstream at regular intervals to take into account soil and irrigation heterogeneity. Fields A and B were irrigated approximately over 7 months at a frequency varying on average between 7 to 12 days. Pasture contributes to the organic fertilisation, a complement being provided by a potassium and phosphorus application at the beginning of the irrigation season at a rate of $150 \mathrm{~kg} / \mathrm{ha}$.

Data collection

Weather measurements:

Rainfall $(\mathrm{P})$, average air temperature $(\mathrm{T})$, relative humidity, daily global radiation $(\mathrm{S})$ and wind speed were measured by a weather station (model 411, Cimel, Paris, France) located on 
the experimental site. These 4 variables are used to calculate Penman Potential Evapotranspiration $\left(\mathrm{ET}_{0}\right)$ which is particularly well suited to the windy conditions of the Crau (Petit, 1981).

\section{Irrigation monitoring:}

Two Parshall flumes were used to measure inlet discharge and runoff. The height of water in the Parshall flumes was provided using water-level probes (model Thalimèdes, messtechnick ${ }^{\circledR}$, Aix en Provence, France). The flow rates calculated as a function of water level head were continuously recorded by a data logger every 15 minutes. Inflow rate was constant (field A: $140 \mathrm{~L} / \mathrm{s}$; field B: $150 \mathrm{~L} / \mathrm{s}$ ) throughout each irrigation event with negligible variation between irrigation events. The control of inflow and outflow rates allowed the assessment of inlet and outlet discharges respectively. Nevertheless, the reliability of runoff measurements is questionable due to the fact that the ditches devoted to evacuate runoff, also act as drainage ditches. Indeed, one often note the presence of water before the advancing front reaches the end of the plot. As outlet discharge is automatically measured (often during the night), it is not possible to separate the amount of water resulting from the sub-surface drainage from that resulting from run-off.

The advance trajectory of the water front was monitored during some irrigation events over the three years. During water supply, the advancing front positioning was obtained with a Global Positioning System (GPS).The recorded data was processed with dedicated software (Map Source of Gamin) associated to the GPS (model Garmin 70CS, Nanterre, France).

\section{Water status monitoring and soil parameter assessments:}

Volumetric Soil Water Content $\theta$ was measured with a neutron probe (model 503 DR, $\mathrm{CPN}{ }^{\circledR}$, Vectra, La Verrière, France) inserted in aluminium access tubes. Before and after irrigation, measurements were performed every $0.1 \mathrm{~m}$ until $1 \mathrm{~m}$ depth and every $0.2 \mathrm{~m}$ from 1 $\mathrm{m}$ to $2.4 \mathrm{~m}$ and repeated for five stations positioned at regular intervals from upstream to downstream ends of the border.

According to the Lacape et al. (1998) approach, two particular values were estimated from neutron probe measurements. Average soil water content at field capacity $\left(\theta_{\mathrm{Fc}}\right)$ and Minimum soil water content $\left(\theta_{\min }\right)$ were determined for these grasslands for the soil depth explored by the roots (Merot et al., 2007). The value of $\theta_{\min }$ was identified in 2004 on the $\mathrm{A}_{2}$ border. A value of 0.28 and 0.12 was assigned to $\theta_{\mathrm{Fc}}$ and $\theta_{\min }$ respectively for the layer 0-70 $\mathrm{cm}$, when lower values $\theta_{\mathrm{Fc}}=0.25$ and $\theta_{\min }=0.15$ were affected to the layer $70-100 \mathrm{~cm}$.

Saturated Water Content $(\theta \mathrm{s})$ was deduced from neutron probe measurements made just after the end of the depletion phase in the upstream part of $A_{1}$. An average value of 0.4 is adopted for this soil parameter.

The Soil Water Fraction which can be Potentially Transpired was evaluated for a one-meter depth by:

$$
\text { PFTSW }=\frac{\int_{0}^{z=1 m}\left(\theta_{F C}(z)-\theta(z)\right) d z}{\int_{0}^{z=1 m}\left(\theta_{F C}(z)-\theta_{\min }(z)\right) d z}
$$

A close comparison between the dynamic over time of PFTSW and the dynamic of herbage growth leads to the evaluation of the ratio between the easily usable reserve (EUR) and the usable reserve (UR) : $E U R / U R=K r$. A Kr value of 0.3 was found in 2004, 2005 and 2006 (Merot et al., 2007). The presence of boulders is the main cause of this low value generally 
http://www.springerlink.com/

DOI 10.1007/s00271-007-0099-3

set at 0.6 for most soils, $\mathrm{Kr}$ ranging from 0.2 to 0.7 according to Doorenbos and Kassam, (1979).

\section{Plant status monitoring:}

Two optical measurements were performed to assess LAI values. LAI was evaluated indirectly by the study of gap fraction analysis (Breda, 2003; Jonckhere et al., 2004 until the herbage reached the averaged height of $0.15 \mathrm{~m}$, at the beginning of the cropping season and just after mowing, This evaluation was performed using hemispherical photography (model fisheye lens, Nikon, Champigny sur Marne, France). Five replicates of 10 photos were taken above the canopy. Then, these numerical photos were processed with Can-eye software (Weiss, 2002).

When the herbage reached $0.15 \mathrm{~m}$, the plant canopy analyser (Model LAI 2000, LICor Inc, Lincoln NE, USA) was used to determine LAI by comparing differential light measurements above and below canopy. A series of 10 measurements were made below canopy and compared to a reference measurement above canopy (Welles and Norman 1991). Five replicates were made for each measurement date. Dry matter (DM) evolution was measured twice a week for each border, on subplots of $0.18 \mathrm{~m}^{2}$ cut at $0.02 \mathrm{~m}$ aboveground using a small clipping machine. Each sample was dried at $60^{\circ} \mathrm{C}$ for $75 \mathrm{~h}$ to assess its dry matter.

The variation coefficients for LAI range from 4 to $20 \%$, the median value being $12 \%$, while those of DM range from 5 to $30 \%$, with a median value of $16 \%$.

\section{Model calibration and evaluation}

SIP calibration and evaluation

The simplest St Venant solution does not provide very significant differences for both advance, and recession when compared to the zero inertia solution of SIRMOD III (Walker, $2003)$ as shown on Fig. 3, in spite of a lower mass conservation error for SIRMOD III $(0.5 \%$ vs $1.5 \%$ ). SIRMOD III is used here, in particular to validate recession phase which was not monitored during our field experiments. Because extended Kostiakov equation $\left(\mathrm{Kt}^{\mathrm{a}}+\mathrm{f}_{0} \mathrm{t}\right)$ is used in SIRMOD III, the latter was preliminarily fitted $\left(\mathrm{K}=0.0348 \mathrm{~m}^{3}, \mathrm{a}=0.249, \mathrm{f}_{0}=\right.$ $0.000049 \mathrm{~m}^{3} \cdot \mathrm{min}^{-1}$ ) to infiltration data generated by $\mathrm{Eq}(3)$ the parameters of which, $\lambda \mathrm{c}$ and Ks, were calibrated for an irrigation event of 2006. To appreciate the quality of model calibration the coefficient of efficiency proposed by Nash -Sutcliffe and defined by:

$$
\mathrm{Ce}=1-\frac{\sum_{i=1}^{N}(\hat{x}(i)-x(i))^{2}}{\sum_{i=1}^{N}(x(i)-\bar{x})^{2}}
$$

, is usually adopted. In $\mathrm{Eq}(19), \mathrm{x}$ and $\hat{x}$, are observed and calculated values respectively. 0.940 is the the value of Ce resulting from the fitting of the extended Kostiakov equation $(\hat{x}(i))$ to the data generated by $\operatorname{Eq}(3)$. The parameter values $\lambda \mathrm{c}=60 \mathrm{~cm}, \mathrm{Ks}=0.75 \mathrm{~cm} \cdot \mathrm{h}^{-1}$ used in $\mathrm{Eq}(3)$ to generate the required $\mathrm{x}(\mathrm{i})$ data for the fitting, are derived from calibration on the advance trajectory of border $\mathrm{A}_{1}$ for irrigation $\mathrm{N}^{\circ} 9$ in 2006 (DOY 180). The value of $\Delta \theta=$ 0.202 , deduced from neutron probe measurements and a $\chi$ value set to 25 (Mailhol, 2003). SIP and SIRMOD III simulate runoff $\left(\mathrm{R}_{0}\right)$ losses values of 6 and $5 \%$ respectively, if the water supply is cut-off when the advancing front reached $\mathrm{x}=380 \mathrm{~m}$ approximately (tco $=440^{\prime}$ ).

Due to the difficulty in measuring the roughness coefficient, $\mathrm{n}$ is set to 0.3 in these simulations. This $\mathrm{n}$ value corresponds to the highest value of the variation domain proposed by Davis et al. (1980) for alfafa borders (0.15-0.3). Highest values, ranging from 0.2 to 0.36 
were obtained using model simulations by Robertson et al., (2004). They did not find any relationship between $n$ and pasture height due to the low flow rates $(0.34 \mathrm{~L} / \mathrm{s} / \mathrm{m})$ used during their field experiments. This value of $n=0.3$ can be justified by the fact that LAI was very high $(\mathrm{LAI}=7.7)$. According to farmers, front advance velocities are influenced by grass height, as advance time is very significantly reduced when irrigation occurs a few days after moving (about one or two hours less than when irrigation takes place before mowing for a 400 m-long border).

The advance monitoring of irrigation $\mathrm{N}^{\circ} 8$ of 2006 on $\mathrm{A}_{1}$ occurring on DOY $=170$ is used to validate the SIP parameters identified for irrigation $\mathrm{N}^{\circ}$ 9. Using $\Delta \theta=0.18$ obtained from neutron probe measurement before irrigation, $\lambda \mathrm{c}=60 \mathrm{~cm}$ and $\mathrm{Ks}=0.75 \mathrm{~cm} / \mathrm{h}$ give a correct simulation of advance trajectory $(\mathrm{Ce}=0.997$ and a Root Mean Square Error: RMSE $=$ $8^{\prime}$ ) with $\mathrm{n}=0.3$, the LAI value being 6.9. But advance trajectory of irrigation $\mathrm{N}^{\circ} 10$, for the same plot, when DOY $=188$ is correctly simulated when $\mathrm{n}$ is set to $0.15(\mathrm{Ce}=0.995$, $\mathrm{RMSE}$ $\left.=9^{\prime}\right)$ instead of $0.3\left(\mathrm{Ce}=0.909, \mathrm{RMSE}=39^{\prime}\right)$. This change can still be justified by a low LAI value $(\mathrm{LAI}=0.87)$ for this irrigation event, which occurred a few days after a moving. This $\mathrm{n}$ value is validated for irrigation $\mathrm{N}^{\circ} 11$ on $\mathrm{DOY}=187$ on $\mathrm{A}_{2}$ which has a comparable LAI value $(\mathrm{LAI}=0.82)$. A validation that used roughness $\mathrm{n}$ values, estimated from LAI simulation, is proposed on Fig4a and Fig4b for 2004.

The data related to the irrigations events monitored for SIP testing are presented in Table 1. From this table, the following relationship can be proposed for predictive purposes:

$$
\mathrm{n}=0.25[1-\exp (-\mathrm{LAI})]+0.05
$$

, 0.05 being the $\mathrm{n}$ value generally adopted for a bare soil. The respective role played by factors such as $\mathrm{n}$ and $\Delta \theta$ in the advance process (Ta (400) = measured or estimated time to reach $\mathrm{x}=400 \mathrm{~m}$ ) can also be identified. For instance, the roles played by $\Delta \theta$ are highlighted when the two last events, which have the same $\mathrm{n}$ value, are compared. As previously explained, measured runoff losses are not reliable enough to be compared with the simulated values. But, one should note that average simulated Ro $=6 \%$, while average measured Ro $=$ $13 \%$.

Due to the infiltration characteristics, and despite water supply being cut-off before the advancing front reaches the end of the plot, the minimum WAD is nearly always greater than $100 \mathrm{~mm}$. Thus, drainage occurs for each irrigation event whatever the location considered within the plot. Consequently, the risk of water stress will only result from irrigation timing (i.e. irrigation frequency).

\section{PILFC calibration}

Model calibration was done on the 2006 irrigation season which contains the most complete and reliable data. The calibration method involves adjusting the LAI shape parameters to a full irrigated treatment when $\lambda$ is calibrated on a plot subject to water stress. Benefiting from frequent irrigation events, dry matter production (Dry Matter DM in T/ha) on the $\mathrm{A}_{2}$ border should be achieved without any water stress, and this assumption is confirmed with tensiometer readings and herbage growth monitoring results (Merot et al., 2007). The LAI data obtained in 2006, and corresponding to the second DM production, are used to fit the LAI shape parameters. The values of $\alpha$, are $\alpha_{1}=3.7, \alpha_{2}=4.4$ and $\beta=3.0$ when a LAImin $=0.75$ is considered. The calibration of the LAI shape parameters (obtained with $\mathrm{Ce}=0.987$ ) is based on a $t_{\mathrm{m}}$ value of $900^{\circ} \mathrm{C}$ derived from the cumulative temperature required to reach the beginning of the LAI plateau on $A_{1}$. The RUEm parameter is derived from the first mowing 
yield (not affected by the peculiar climatic conditions previously described) while Tmat is derived from the production plateau of the third mowing. The experimental estimate of Tmat is based on observations of the end of flowering. The respective values of these two parameters are $0.37 \mathrm{gMJ}^{-1}$ and $1020 \mathrm{C}^{\circ}$.

At this calibration stage, the effect of severe windy conditions (inducing high $\mathrm{ET}_{0}$ rates) on the DM production is tested. Initially, the threshold value $\mathrm{EXT}_{0}$ was selected from a climatic data analysis. It was established that $\mathrm{ET}_{0}$ values greater than $\mathrm{EXT}_{0}=8$, were generally the result of severe windy conditions. Note that such high $\mathrm{ET}_{0}$ values are rarely observed before the beginning of the second mowing.

Using model simulations, a value of 5 for $\xi$, was adopted to match the average yield losses proposed by the experts. The HC production rate of 2004, unlike those of 2005 and 2006 , is not affected by the correction of RUEm, which is verified by the model simulations. A test of sensitivity performed on 2005 and 2006 shows that DM production of the $2^{\text {nd }}$ and $3^{\text {rd }}$ mowing is increased by 5 and 3\% respectively when diminishing $\xi$ by $40 \%$. DM production of the $2^{\text {nd }}$ and $3^{\text {rd }}$ mowing is reduced by $3 \%$ for a $\xi$ increase of $40 \%$.

The cumulative temperature from DOY $=1$ is $\mathrm{T}_{\mathrm{ds}}=2800^{\circ} \mathrm{C}$, until approximately the second harvesting date. We obtained a value of $510^{-3}$ for $\varsigma$ which gives a satisfactory simulation of the dry matter production for the third mowing $\left(2.6 \mathrm{~T}^{\mathrm{T}} \mathrm{ha}^{-1}\right)$. LAI of the third mowing (Fig. 5a) is not as well simulated as the DM production rate (Fig. 5b) of plot $\mathrm{A}_{2}$. A test of sensitivity conducted in the same conditions as for $\xi$, shows that DM production of the last mowing is reduced by $11 \%$ when $\varsigma$ is increased by $50 \%$ and increased by $7 \%$ when $\varsigma$ is reduced by $30 \%$. Consequently, both $\xi$, $\varsigma$ are not very sensitive parameters.

Before dealing with the water stress problem, the soil parameters have to be identified. Our soil surveys and soil profile analysis attest to the presence of boulder loam the density of which strongly increases with depth exceeding $0.6 \mathrm{~m}$. From these previous considerations, and according to soil water analysis indicating the range within which soil water content can vary, a soil water content at field capacity $\theta_{\mathrm{Fc}}=0.28$ and the minimum humidity observed $\theta_{\text {min }}$ $=0.12$ are assigned to reservoirs $R_{1}$ and $R_{2}$ respectively, with $Z_{1}+Z_{2}=0.6 \mathrm{~m}$ when $\theta_{\mathrm{Fc}}=0.25$ and $\theta_{\min }=0.15$ are assigned to $R_{3}$. Although there are certainly no roots below $0.7 \mathrm{~m}$, soil water balance estimation is performed on $\mathrm{Zr}=1 \mathrm{~m}$. This probable root depth overestimation compensates for a potential capillary rise effect that would require a supplementary parameter.

The low $\mathrm{Kr}$ value of 0.3 concurs with the amount of water consumed by plants and corresponds to the difference between field capacity and the soil water content at which plants begin to manifest water stress.

Border $A_{1}$ is used for $\lambda$ calibration as it was significantly affected by water stress and particularly so for the third DM production. A value of 10 for the latter allowed us to obtain a satisfactory LAI simulation (Fig. 6a), and also gave acceptable values for herbage growth along the season for this same border (Fig. 6b).

Using $\mathrm{K}_{\mathrm{cx}}=1$, as proposed by literature for grass (Allen et al., 1998), the soil water balance is satisfactorily simulated for the two borders (Fig.7a and Fig.7b) in 2006. Each reservoir was initialised at field capacity on DOY $=30$; the date at which the production started with an initial value of $\mathrm{LAI}_{0}=2$.

With $\mathrm{Eq}(10)$, it is possible to account for a radiation deficit impact on LAI. But due to the climatic conditions of the region, we chose to ignore this impact by setting $S_{\text {opt }}$ at a value of $15 \mathrm{MJ}^{-2}$. A sensitivity analysis of this parameter shows that increasing $\mathrm{S}_{\mathrm{opt}}$ from 15 up to 18 $\mathrm{MJ}^{-2}$ would result in an average LAI diminution of $0.25 \mathrm{~m}^{2} / \mathrm{m}^{2}$ and a DM loss of $0.2 \mathrm{~T} / \mathrm{ha}$ on the basis of the climatic scenario of 2005 .

\section{PILFC Evaluation}

DM accumulation and LAI 
Model evaluation for DM accumulation and LAI 2005 is presented in Fig. 8 and Fig. 9. Because of the experimental protocol, model verification for 2004 is based on DM, which was manually harvested on the yield sub-plots for the last mowing (Fig.10). A slight overestimation of DM was observed for the beginning of each production season whatever the year. However, despite a few gaps (in particular for the $3^{\text {th }}$ mowing of $A_{2}$ in 2005), LAI and herbage growth are considered to have been correctly simulated. Lastly, manually harvested DM production is quite well simulated for the 3 years (Fig. 11).

\section{Soil Water Reserve}

As attested by Fig.7. SWR is correctly simulated in 2006 with RMSE close to $10 \mathrm{~mm}$. In 2005 , the quality of the simulation is a little better for $\mathrm{A}_{1}(\mathrm{Ce}=0.86 ; \mathrm{RMSE}=6.4 \mathrm{~mm})$ and $\mathrm{A} 2(\mathrm{Ce}=0.87 ; \mathrm{RMSE}=6.4 \mathrm{~mm})$. In 2004, RMSE values were not as satisfactory for the two plots $\mathrm{A}_{1}$ and $\mathrm{A}_{2}(0.72>\mathrm{Ce}>0.60$ and $22>\mathrm{RMSE}>20 \mathrm{~mm})$. Attested gaps highlight an overestimation of SWR for an intense deficit (SWRD > 70\%), while those of 2005 and 2006 can be considered as moderate (SWRD $<65 \%$ ). But, due to the high sensitivity of grassland to moderate water deficit (Merot et al., 2007), and with the prospect of model utilisation for HC management, a moderate SWRD should only be taken into consideration.

Consequently, one can reasonably attest that SWR and DM production are both satisfactorily simulated by PILFC.

\section{SPFC: The SIP-PILFC coupling}

Assuming a homogeneous soil border (soil, plant and deficit before irrigation), WAD heterogeneity can only result from opportunity time variability. The border is divided into subplots of $10 \mathrm{~m}$ length, for which WAD is considered to be homogeneous. PILFC runs on each subplot of $1 \times 10=10 \mathrm{~m}^{2}$ with a WAD simulated by SIP. The latter in turn, makes use of $\Delta \theta$ (for Eq.(3)) and LAI (for Eq.(20)) values predicted by PILFC to simulate the irrigation event. As WAD, at the level of each subplot, exceeds field capacity, PILFC does not simulate any $\mathrm{HC}$ production differences from upstream to downstream. Consequently, yield variability cannot be used as a criterion to validate this model coupling.

\section{SPFC application:}

Using model simulations, it is possible to test some irrigation strategies combined with realistic plots sizes to assess whether water can be saved while still achieving the required yield level and production quality. Plot size reduction can be obtained by changing flow direction, the inflow rate being set at Qin $=3 \mathrm{~L} / \mathrm{s} / \mathrm{m}$. Of course, this operation requires plot leveling in a direction perpendicular to the previous flow, the initial $450 \mathrm{~m}$ long plot being divided into two $200 \mathrm{~m}$ long plots of which $2 \times 25 \mathrm{~m}$ is devoted to the water supply and the runoff ditches. In agreement with irrigation practices, the irrigation season starts on DOY $=70$ and stops on DOY=240.The results of the simulation, based on the climatic scenario of 2005, are summarized in Table 2. One can see that a significant amount of water can be saved when by roughly dividing the plot length by 2 and scheduling irrigation for a soil water reserve depleted (SWRD) at $50 \%$. For a field length $\mathrm{FL}=450 \mathrm{~m}$ water supply is cut-off when the advancing front reaches $\mathrm{x}=0.85 \mathrm{FL}$ and at $\mathrm{x}=0.77 \mathrm{FL}$ for $\mathrm{FL}=200 \mathrm{~m}$. The scheduling option $\mathrm{SWRD}=50 \%$ which reduces the irrigation frequency, slightly affects the maximum yield value (8.6 Vs $9.5 \mathrm{~T} / \mathrm{ha})$. It requires less water but above all less manpower: 8 irrigation events cumulating at a total water application (TWA) of $10820 \mathrm{~m} 3 /$ ha against 11 giving a TWA of $14600 \mathrm{~m} 3 /$ ha. Note that scheduling, allows substantial water savings compared with the current farmer strategy simulated by SPFC (first line of Table 2).

The application efficiency (Burt et al., 1997) of the solution resulting in best water savings has by far the highest value $(\mathrm{AE}=56 \%)$. This solution provides an acceptable 
uniformity coefficient $(\mathrm{UC}=80 \%)$ and weak runoff losses $(\mathrm{Ro}=2 \%)$ and one can assume that groundwater recharge can be still guaranteed with an averaged drainage value D of 500 $\mathrm{mm}$. These simulation results highlight the role that an efficient scheduling method could play in reducing water losses. Indeed, on the basis of the potential yield (9.5 T/ha) about 5000 $\mathrm{m} 3 /$ ha of water could be saved.

Of course border length reduction allows water savings. But the pertinence of this solution with regards to labor savings cannot be analyzed without taking into account the whole range of constraints existing at farm level, A solution that would merit assessment by the future DSS in which the SPFC will be integrated, is the watering of two $200 \mathrm{~m}$ long borders by day to verify if night irrigation could be avoided.

\section{Conclusion}

The modelling approach for managing water and $\mathrm{HC}$ production at plot level was described. The model results from the coupling of a predictive border irrigation model with a crop model, which were both successfully validated. The crop model estimates water balance and $\mathrm{HC}$ production on $\mathrm{k}$ subplots along the border. It provides the initial soil water content so that the infiltration equation of the border model can be updated before each irrigation event and the LAI value to be calculated for the estimation of $n$, the roughness coefficient. Although this crop model was specifically developed for the HC production, some modelling aspects such as those governing species evolution or high evapotranspiration rates (provoked by strong wind) can be easily ignored using appropriate thresholds. For instance, adopting a very high value for $\mathrm{T}_{\mathrm{ds}}$, eliminates the species effect, thus allowing the simulation of a single species such as lucerne. This allows the enlargement of the model's field of application

SPFC simulations show that it is difficult to significantly improve application efficiency (AE) and to save water without affecting $\mathrm{HC}$ production within the current context of irrigation practices. Nevertheless, using scheduling methods based on a soil water depletion threshold of 40 or even $50 \%$, would allow substantial water savings (close to 5000 $\mathrm{m} 3 / \mathrm{ha}$ ) compared with current farmers' practices without significant yield losses (around a $10 \%$ reduction for the $50 \%$ threshold). One can assume that drainage losses, which are greatly reduced, are still compatible with groundwater recharge required for regional ecosystem sustainability and in the provision of an adequate potable water supply.

The solution based on border length reduction, which is designed to save both water and labour, must be analyzed at farm level rather than plot level. This would allow the different constraints to be taken into account. One can expect that the future DDS, which will integrate SPFC, will make this type of analysis possible and, will contribute to the improvement of water management and hay production in the Crau region.

\section{Acknowledgements:}

The authors would like to especially thank Mr François Charron, who is in charge of the Merle Domain experiments, for his valuable assistance in data collection.

\section{Notation:}

$\mathrm{AE}=$ Application Efficiency $(\%)$

$\mathrm{AT}_{\mathrm{Pi}}=$ Actual transpiration of a layer i $(\mathrm{mm})$

$\mathrm{Cp}=$ Partitioning coefficient linked to LAI (Leaf Area Index) 
Original version at Springer site -

http://www.springerlink.com/

DOI 10.1007/s00271-007-0099-3

DOY = Day of The Year

$\mathrm{d}_{\mathrm{i}}=$ drainage from layer $\mathrm{i}$

Es $=$ Soil evaporation $(\mathrm{mm})$

$\mathrm{ET}_{0}=$ Reference evapotranspiration (mm)

$\mathrm{EXT}_{0}=$ Threshold of $\mathrm{ET}_{0}$ over which RUE is affected.

$\mathrm{FL}=$ Field (or border) Length $(\mathrm{m})$

$\mathrm{k}=$ extinction coefficient used in the Dry Mater accumulation estimation (-)

$\mathrm{Kr}=$ Easily Usable Water Reserve/Usable Water Reserve (-)

$\mathrm{Ks}=$ Saturated conductivity $(\mathrm{cm} / \mathrm{h})$

$\mathrm{Kc}=$ Crop coefficient (-)

$\mathrm{K}_{\mathrm{cx}}=$ Maximal crop coefficient value (-)

$\mathrm{LAI}_{\max }=$ Maiximal Leaf Area Index (-) value in Eq(10)

$\mathrm{LAI}_{\min }=$ Minimal LAI value after a mowing.

$\mathrm{LAI}^{*}=\mathrm{LAI}$ value calculated without no stress

$\mathrm{LAI}_{0}=$ initial LAI value (either at the end of winter or after a mowing) in $\mathrm{Eq}(10)$

$\mathrm{MET}=$ maximal evapotranspiration $=\mathrm{Kc} \mathrm{ET}_{0}$

$\mathrm{n}=$ Roughness coefficient $\left(\left[\mathrm{L}^{1 / 3}\right][\mathrm{T}]\right)$

$\mathrm{RGSI}=$ a radiation stress index $(-)$ in $\mathrm{Eq}(10)$

Ro $=$ Runoff losses $(\%)$

$R p(j)=$ ratio between two cumulative leaf area index $(\mathrm{CLAI} / \mathrm{CLAI} *)$ on 3 days preceding the day j.

$\mathrm{R}_{\mathrm{i}} \sup =\left(\theta_{\mathrm{Fc}} \cdot-\theta_{\text {mii }}\right) Z_{\mathrm{i}}=$ Usable Water Reserve for a $\mathrm{Z}$ depth soil layer $\mathrm{i}$

RUEm = average Radiation Use Efficiency $\left(\mathrm{gMJ}^{-1} \mathrm{~m}^{-2}\right)$

$\mathrm{S}(\mathrm{j})=$ daily radiation $\left(\mathrm{MJm}^{-2}\right)$

$\mathrm{S}_{\mathrm{opt}}=$ daily radiation value under which $\mathrm{LAI}$ can be affected. $\left(\mathrm{MJm}^{-2}\right)$

SWR $=$ Soil Water Reserve $(\mathrm{mm})$

$\mathrm{SWRD}=$ soil water reserve depletion $(\%)$

$\mathrm{S}_{0}=$ field slope $(\%)$

$\mathrm{Ta}=$ advance time $(\mathrm{min})$

TAET $=$ Total Actual Evapotranspiration $(\mathrm{mm})$

$\mathrm{T}_{\mathrm{ds}}=\mathrm{a}$ temperature $\left(\mathrm{C}^{\circ}\right)$ threshold from which RUE decreases due to species death

$\mathrm{t}_{\mathrm{m}}=$ cumulative temperature threshold $\left(\mathrm{C}^{\circ}\right)$ to reach $\mathrm{LAI}_{\max }$

$\mathrm{Tp}_{\mathrm{i}}=$ Potentiel transpiration of a layer $\mathrm{i}$

TWA $=$ Total Water Application (mm)

$\mathrm{UC}=$ Uniformity Coefficient $(\%)$

$\mathrm{WAD}=$ Water Application Depth $(\mathrm{mm})$

WSI $=$ a water stress index (-) in $\operatorname{Eq}(10)$

$\alpha, \beta=$ LAI shape parameters (-) in $\mathrm{Eq}(10)$

$\Delta \theta=\theta \mathrm{s}-\theta \mathrm{i}=$ Saturation deficit (-)

$\lambda=$ a parameter (-) ruling the WSI impact in $\mathrm{Eq}(10)$

$\lambda \mathrm{c}=$ Capillary length $(\mathrm{cm})$

$\chi=$ a parameter (-) governing the macro-pore effect

$\varsigma=$ a parameter $\left(\mathrm{C}^{-1}\right)$ involved in the RUE decrease due to death species

$\xi=$ a parameter (-) ruling the sensitivity of RUE to high $\mathrm{ET}_{0}$ values (i.e. windy conditions of the Crau region)

$\theta_{\mathrm{fc}}=$ Volumetric soil water content at field capacity (-)

$\theta_{\min }=$ Minimum volumetric soil water content (-)

$\theta \mathrm{i}=$ initial volumetric soil water content (-)

$\theta \mathrm{s}=$ Saturated volumetric water content (-) 


\section{References:}

Allen, R.G., Pereira L.S, Raes, D., Smith, M., (1998). Crop evapotranspiration : Guidelines for computing crop water requirements . Irrig and Drain. Paper 56 FAO, Rome.

Allison B.E., Fechter, J., Leucht, A., Sivakumar, M.V.K., (1993). The use of CERES-MILLET model for production strategy analysis in south west Niger. $15^{\text {th }}$ Congres on irrigation and drainage . $2^{\text {nd }}$ Workshop on crop Water Models .The Hague, the Netherlands 1993. Session III p 17.

Balland P., P. Huet, E. Lafont, J.P. Leteurtrois and P. Pierron. (2002). Propositions de simplification et de modernisation du dispositif d'intervention de l'Etat sur la gestion des eaux et du lit de la Durance - Contribution à un Plan Durance. Paris: Ministère de l'Ecologie et du Développement Durable, Ministère délégué à l'Industrie, Ministère de l'Agriculture, de la Pêche et des Affaires Rurales, Ministère de l'Equipement, des Transports, du Logement, du Tourisme et de la Mer.

Boutin J. and G. Cheylan (2004). "Natural areas in the Crau " Int. J. Mediterranean Ecol. 30(1): Special issue.

Breda N.J.J., (2003). Ground-based measurements of leaf area index: a review of methods, instruments and current controversies. J. Exper. Bot.. 54 (392): 2403-2417.

Burt C., , Clemmens A.., Strelkoff T., Solomon K., Bleisner R., Hardy L, Howell T., Eisenhauer D., (1997). Irrigation performance measures. Efficiency and uniformity, J. Irrigation and Drainage Engineering 123(6) : 423-442.

Calvière I. and Duru M, (1995), Leaf appearance and senescence patterns of some pasture species. Grass Forage Sci.. 50: 447-451.

Corson M.S., Skinner R.H., Rotz C.A., (2006). Modification of the SPUR rangeland model to simulate species composition and pasture in humid temperate regions. Agricultural systems, 87, 169-191.

Doorenbos J. and Kassam, A.H., (1979), Yield response to water, irrigation and drain. Paper n³3, FAO, Rome, (Italie), 235p.

FAO-UNESCO. (1981). "Soil map of the world - 1/5.000.000".FAO, Rome.

Green W.H., and Ampt, G.A., (1911). Studies on soil physics: I. The flow of air and water through soils. J. Agric. Sci. 4: 1-24.

Jonckheere I., Fleck S., Nackaerts K. Muys B., Coppin P., Weiss M., Baret F., (2004). Review of methods for in situ leaf area index determination. Part I: Sensors and hemispherical photography. Agric. Forest Meteorol.. 121: 19-35.

Kostiakov A.N., (1932). On the dynamics of the coefficient of water-percolation in soils and on the necessity of studying it from a dynamic point of view for purposes of amelioration. Trans.

Sixth Comm. Intl. Soc. Soil Sci., Part A. 17-21.

Lacape M.J., J. Wery, et al. (1998). "Relationships between plant and soil water status in five fieldgrown cotton (Gossypium hirsutum L.) cultivars." Field Crops Rech. 57: 29-43.

Mailhol J.C. and Gonzalez, JM., (1993). A furrow irrigation model for real time applications on cracking soils - J. Irrig. Drain. Engin., ASCE, Vol 119 N5 Sept/Oct 1993, 768-783p.

Mailhol J.C., O. Olufayo, P. Ruelle, (1997). AET and yields assessments based on the LAI simulation. Application to sorghum and sunflower crops. Agric. Water Manag, 35(1997) 167$182 \mathrm{p}$.

Mailhol J.C., Priol M., Benali M. (1999). A furrow irrigation model to improve irrigation practices in the Gharb valley of Moroco. Agric. Water Manag.. 1475 (1999) 1-17

Mailhol J.C., (2003). A predictive form of Horton's equation for simulating furrow irrigation. J. Irrig.and Drain. ASCE, Vol 129 (6): 412-421.

Mailhol J.C., Zaïri A., Slatni A., Ben Nouma, B., El Amami, H., (2004). Analysis of irrigation systems and irrigation strategies for durum wheat in Tunisia'Agric.Water Manag.(70), 19-37.

Mailhol J.C., Ruelle P., and Z. Popova, (2005). SOFIP: A field-scale modelling of water management and crop yield for furrow irrigation. Irrig. Sci. (24): 37-48.

Merot A. Wery J., Isbérie C., and F. Charron, (2007). Response of multi-species grassland to border irrigation regulated by tensiometers. European . J. of Agronomy. 28(1),1-8. 
Moussi M., Saki, T., (1953). Uber den lihtfaktor in den Plantrzngesllschaften und seine Beidentung fur die Stoffprodktion. Jpn. T. Bot. 14, 22-52.

Novak V., (1981). The structure of evapotranspiration I and II Vodohosp Cas 35, 3-21, in Slovak.

Petit V., (1981). Etude et modélisation de la variabilité de l'évapotranspiration réelle - Application au bilan hydrologique de la plaine de Crau. Ecole Nationale Supérieure des Mines de Paris Université Pierre et Marie Curie - Paris VI, p114.

Philip J.R., (1973) On solving the unsaturated flow equation: 1. The flux-concentration relation. Soil Sci. 116: 328-335.

Rayej, M, (1985). Furrow irrigation time reduction. J of Irrig. Drain., ASCE , Vol 111, NO 2 : 134146

Richards L.A., (1931). Capilllary conduction of liquids through porous media. Physics 1:318-333.

Robertson, D., Wood, M and Wang, Q.J., (2004). Estimating hydraulic parameters for surface irrigation model from field condition. Australian Journal of Experimental Agriculture. 44 (2), 173-179.

Rosenbrock H., (1960). An automatic method for finding the greatest or the least value of a function. Comput. J., 3, 175-184.

Saos J.L, Belaud, G., Charron F., Le Goulven, P., (2006). Quantification des flux d'eau en irrigation gravitaire en Crau - Rapport final . UMR G-Eau -Supagro. 270p.

Saucedo H., Fuentes, C., Zavala, M., (2005). The St Venant and Richards equation system in surface irrigation: numerical coupling for the advance phase in border irrigation. Ingenierie hidraulica en Mexico, (20(2), 109-119.

Strelkof T..and Katapodes, N.D, (1977) Border irrigation hydraulics with zero inertia. J of Irrig. and Drain. Divis. ASCE., Vol 102 No IR3, Proc. Paper 13199, 325-342.

Strelkof T.., Clemmens, A.J., Schmidt, B.V., Slosky, E.J., (1996). A design and management aid for sloping border irrigation systems. US Department of Agric. Research Service U.S Water Conserv. Lab. 4331 E. Broadway, Phoenix, AZ 85040, June 1996.

Walker WR., and Humpherys, A.S., (1983). Kinematic wave furrow irrigation model. J. Irrig. Drain. Engin. ASCE, Vol 116 NO 3, 299-318.

Walker WR , (1993). SIRMOD, a surface irrigation model. Utah State University Depart of .Biol. and irrig. Engin., UTAH State University Logan UT 84322-4105.

Walker WR , (2003). SIRMOD III, a surface irrigation software. Course guide and technical documentation. Depart of Biological and irrig. Engin., UTAH State University Logan UT $84322-4105$.

Weiss M., (2002). www Avignon.inra.fr/can_eye/

Welles J.M. and Norman J.M, (1991).Instrument for indirect measurement of canopy architecture. Agron. J. 83(5): 818-825.

Zatarian F.C.,Fuentes, Rendon, L., Vauclin, M., (2003). Effective soil hydrodynamic properties in border irrigation. Hydraulic engineering in Mexico. Ingeniera hidraulica en Mexico, 18(3), 5-

15. 
Table 1. SIP simulation results under the different irrigation conditions $(\mathrm{Ta}(400)=$ advance time (in $\mathrm{min}$ ) to reach the abscissa $\mathrm{x}=400 \mathrm{~m}$ )

\begin{tabular}{ccccccccc}
\hline Y -DOY & Plot & Qin $(\mathrm{L} / \mathrm{s} / \mathrm{m})$ & LAI & $\mathrm{n}$ & $\Delta \theta$ & $\mathrm{Ta}(400)$ & $\mathrm{Ce}$ & RMSE (min) \\
\hline $2004-153$ & A1 & 3.1 & 1.3 & 0.2 & 0.160 & 375 & 0.999 & 3.6 \\
$2004-222$ & A1 & 3.1 & 4.5 & 0.3 & 0.207 & 486 & 0.998 & 6.5 \\
$2004-242$ & B1 & 4.1 & 1.6 & 0.2 & 0.230 & - & 0.994 & 6.7 \\
$2004-214$ & A2 & 2.8 & 3.5 & 0.3 & 0.230 & 567 & 0.998 & 5.6 \\
$2005-180$ & A2 & 3.0 & 3.4 & 0.3 & 0.202 & 475 & 0.991 & 11.2 \\
$2005-215$ & A2 & 3.0 & 5.9 & 0.3 & 0.213 & 475 & 0.976 & 18.8 \\
$2006-170$ & A1 & 3.1 & 6.9 & 0.3 & 0.180 & 460 & 0.997 & 8.0 \\
$2006-180$ & A1 & 3.1 & 7.7 & 0.3 & 0.202 & 480 & 0.999 & 5.0 \\
$2006-177$ & A2 & 3.1 & 7.9 & 0.3 & 0.190 & 470 & 0.987 & 22.0 \\
$2006-187$ & A2 & 3.1 & 0.82 & 0.15 & 0.190 & 420 & 0.994 & 10.0 \\
$2006-188$ & A1 & 3.1 & 0.87 & 0.15 & 0.173 & 380 & 0.995 & 9.0 \\
\hline
\end{tabular}

Table2. Example of simulation results combining irrigation scheduling strategies (for an Irrigation period from DOY $=70$ to DOY $=250$ ) with plot sizes for the climatic scenario of 2005 (the water supply is cut-off when the advancing front reaches $85 \%$ of FL $=450 \mathrm{~m}$ and $77 \%$ of $\mathrm{FL}=200 \mathrm{~m}) . \% \mathrm{SWRD}=$ depletion level of the soil water reserve, $\mathrm{AE}=$ application efficiency, TWA = Total Water Application, NIV number of irrigation events during the season, $\mathrm{D}=$ drainage losses, $\mathrm{Y}=$ yield, $\mathrm{UC}=$ uniformity coefficient, $\mathrm{Ro} \%=$ runoff losses (AE, D, UC, Ro are averaged values calculated from 8 or 11 irrigation events). The first line refers to the simulation of traditional irrigation practices in 2005.

\begin{tabular}{ccccccccc}
\hline $\mathrm{L}(\mathrm{m})$ & \%SWRD & AE\% & TWA(m3/ha) & NIV & D(mm) & Y(T/ha) & UC(\%) & Ro(\%) \\
\hline 450 & - & 26 & 24500 & 15 & 1600 & 9.3 & 88 & 10 \\
\hline 450 & 40 & 35 & 19170 & 11 & 1150 & 9.5 & 87 & 8 \\
450 & 50 & 42 & 14300 & 8 & 800 & 8.6 & 86 & 6 \\
200 & 40 & 47 & 14600 & 11 & 800 & 9.5 & 85 & 4 \\
200 & 50 & 56 & 10820 & 8 & 500 & 8.6 & 80 & 2 \\
\hline
\end{tabular}




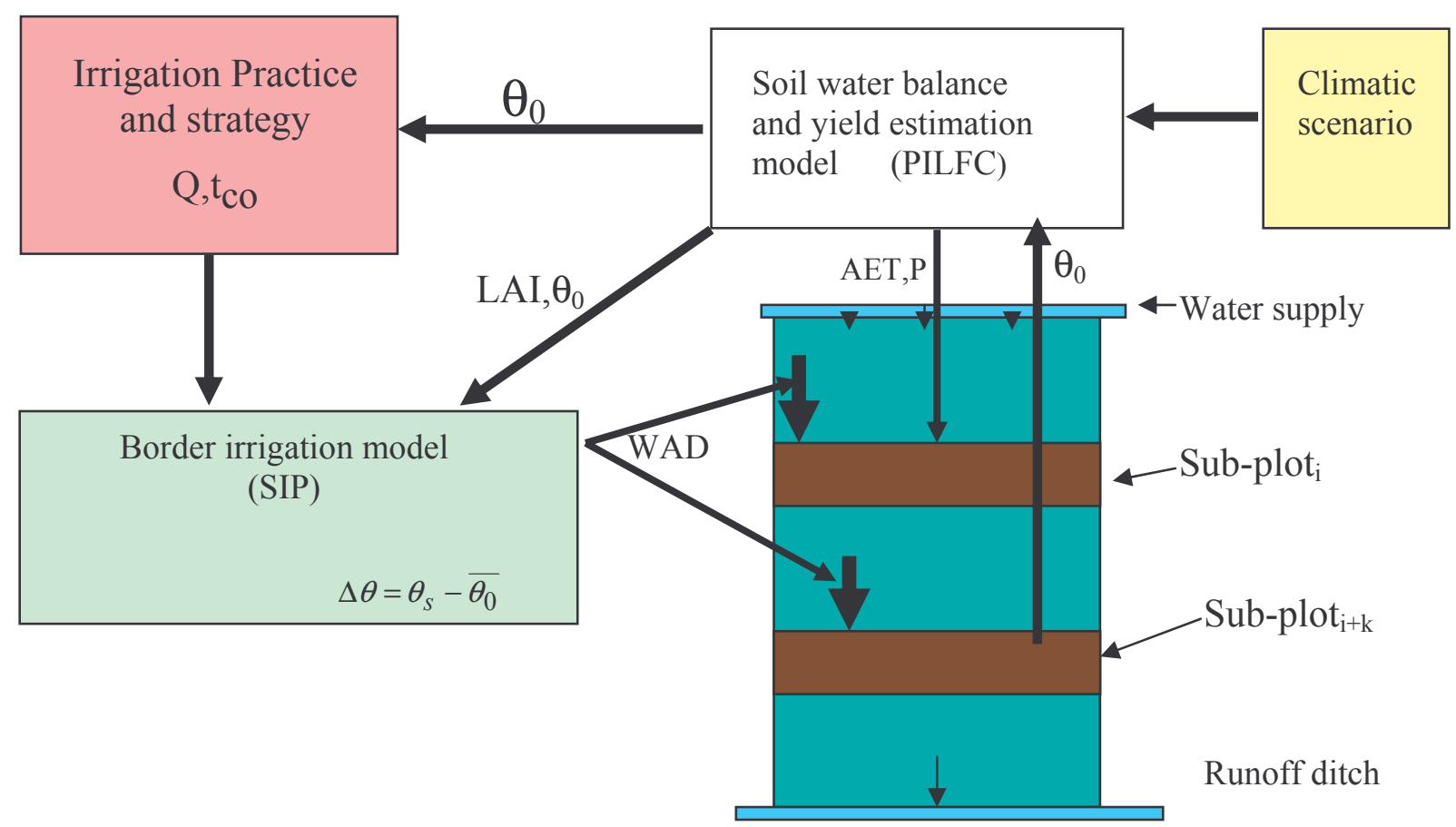

Fig.1 Overview of the modelling approach (P precipitation, AET actual evapotranspiration and WAD calculated by SIP are data used by PFC to calculated initial soil water conditions $\theta_{0}$ for the whole of sub-plots. and LAI used to adapt SIP to new roughness border conditions) 

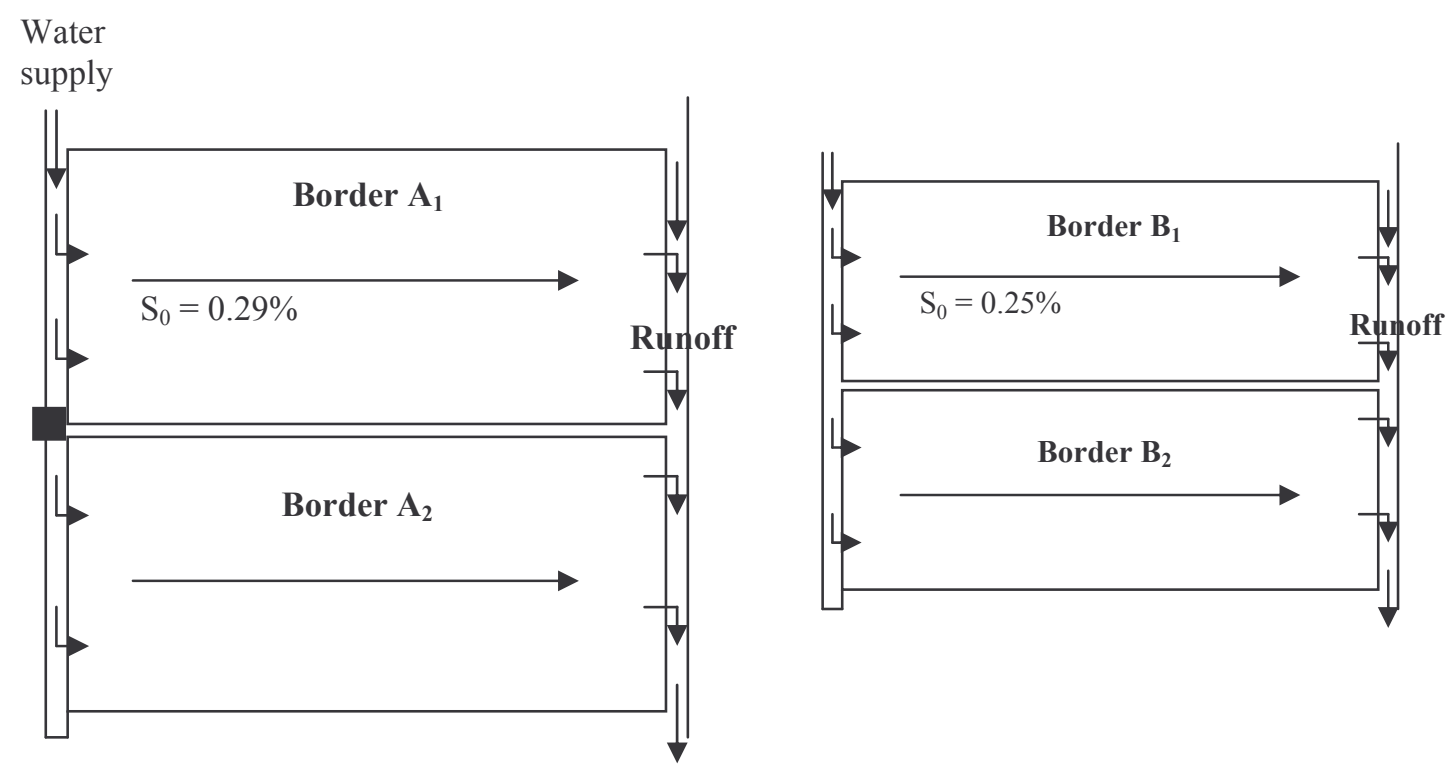

Fig 2. Experimental field setup: two permanent grasslands A: $450 \mathrm{~m}$ long and $90 \mathrm{~m}$ width, B: $325 \mathrm{~m}$ long and $66 \mathrm{~m}$ width. Both are divided into irrigation borders. $\mathrm{A}_{1}$ and $\mathrm{A}_{2}$ are supplied by a constant inflow rate of 140 when $B_{1}$ and $B_{2}$ by a constant flow rate of $150 \mathrm{~L} / \mathrm{s}$. 

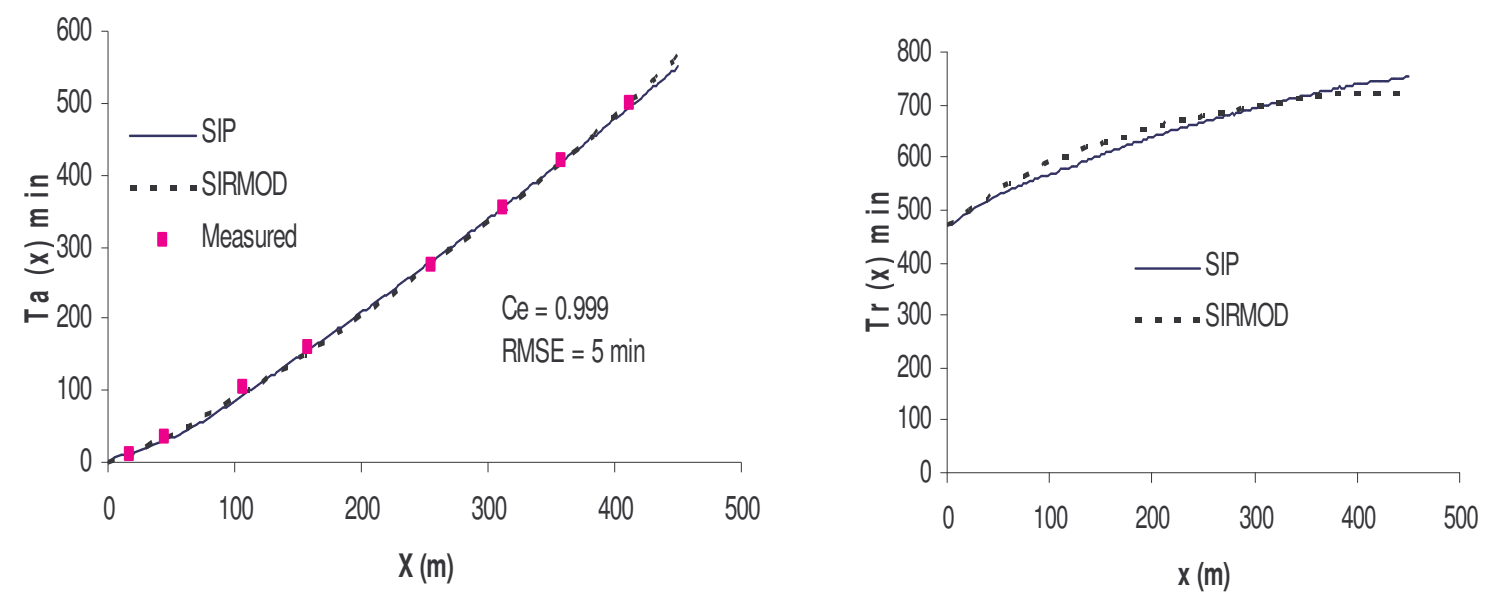

Fig.3 SIP Vs SIRMOD (with zero inertia solution), calibration on advance trajectory (a) on irrigation $\mathrm{N}^{\circ} 7, \mathrm{DOY}=180$ in 2006 on plot $\mathrm{A}_{1}$, and recession (b). Water was cut-off when the advancing front reached $\mathrm{x}=380 \mathrm{~m},\left(\mathrm{t}_{\mathrm{co}}=440^{\circ}\right) \lambda \mathrm{c}=60 \mathrm{~cm}, \mathrm{Ks}=0.75 \mathrm{~cm} / \mathrm{h}, \Delta \theta=0.202, \mathrm{n}$ being set to $0.3(\mathrm{LAI}=7.7)$. 

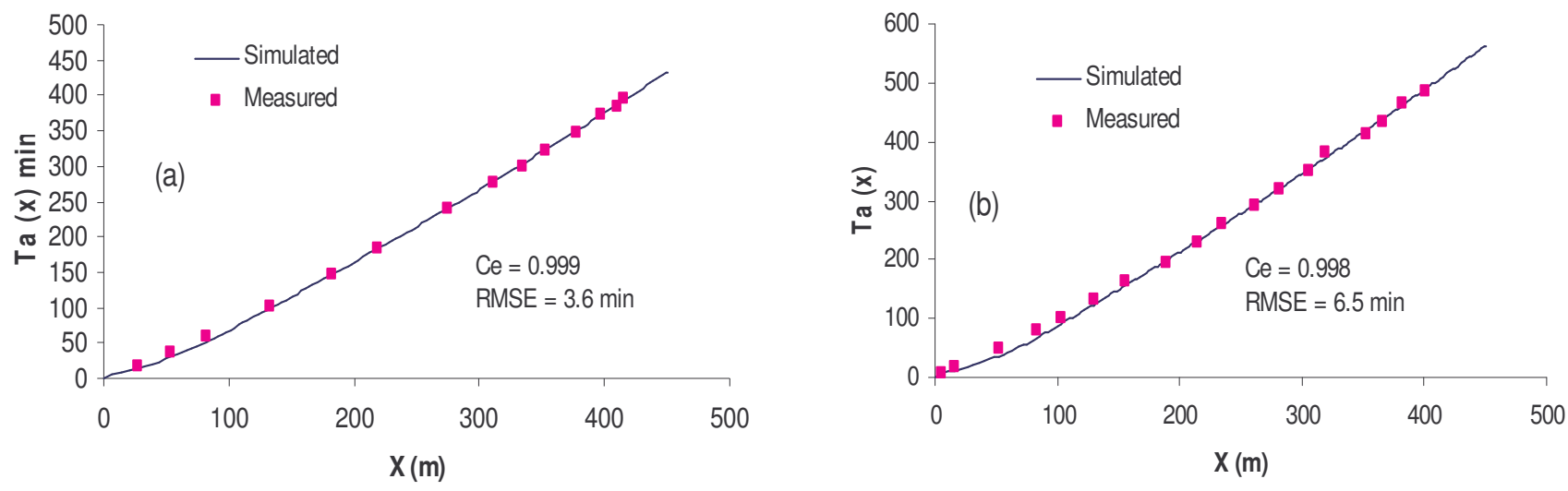

Fig 4. SIP validation on irrigation $\mathrm{N}^{\circ} 7$ on $\mathrm{DOY}=153$ of 2004 on $\mathrm{A}_{1}(\mathrm{a}), \Delta \theta=0.16$, with $\mathrm{n}=$ $0.2(\mathrm{LAI}=1.3)$ and on irrigation $\mathrm{N}^{\circ} 14$ on $\mathrm{DOY}=222$ of 2004 on $\mathrm{A}_{1}(\mathrm{~b}), \Delta \theta=0.207$, with $\mathrm{n}$ $=0.3(\mathrm{LAI}=4.5)$ 

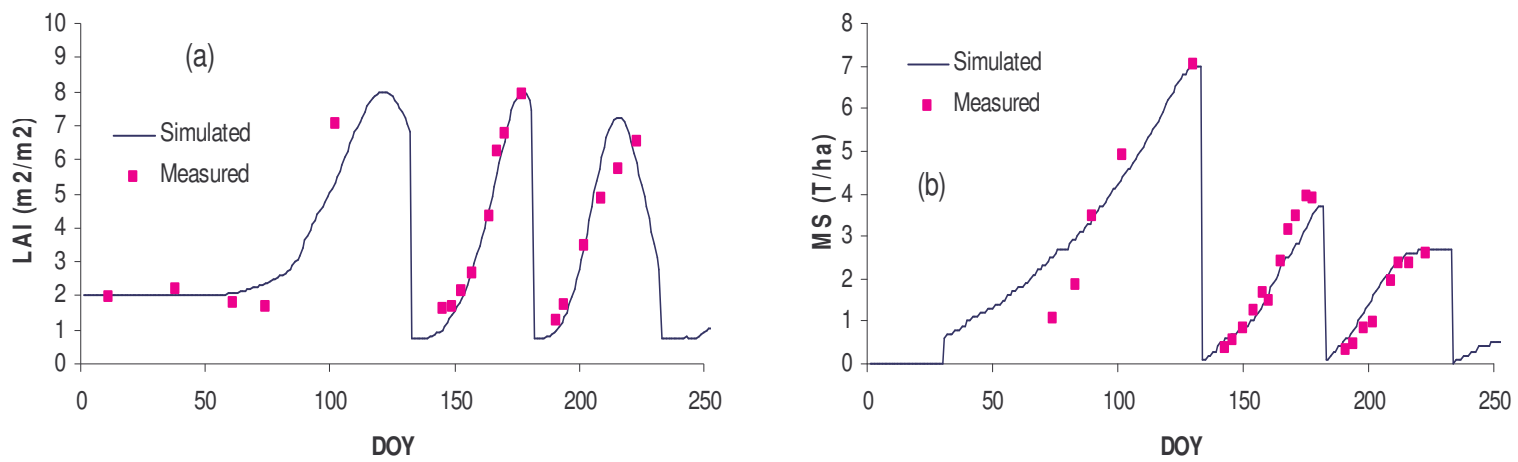

Fig 5 LAI (a) and the DM production (b) for $\mathrm{A}_{2}$ plot in 2006 

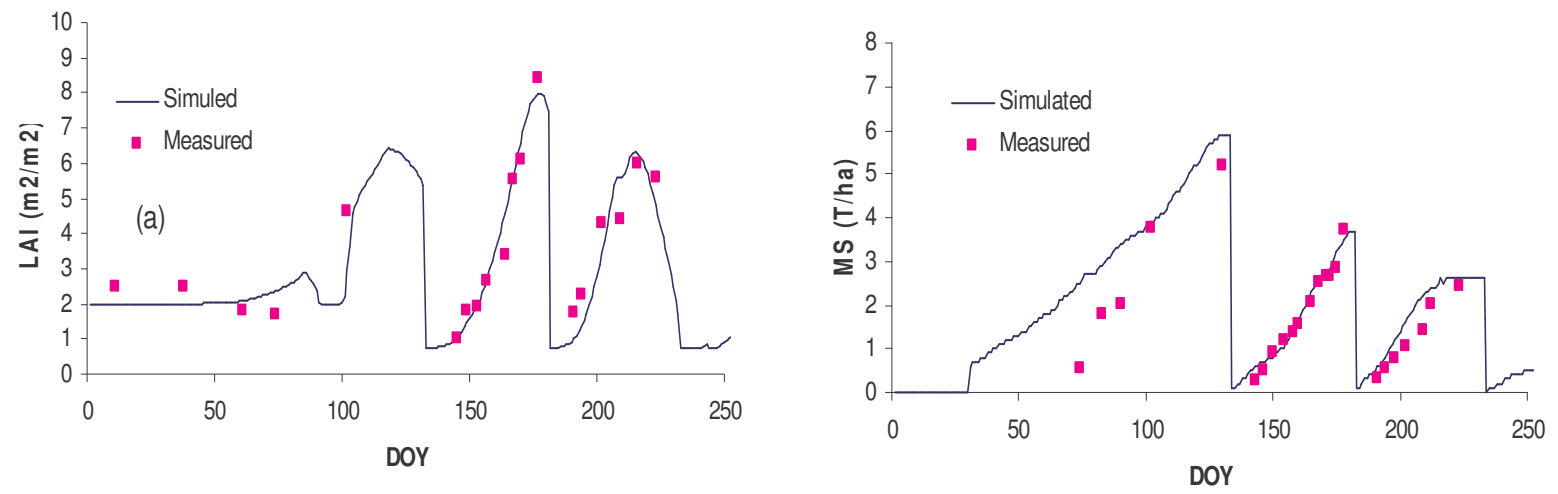

Fig. 6 LAI (a) and the DM production (b) for $\mathrm{A}_{1}$ plot in 2006 

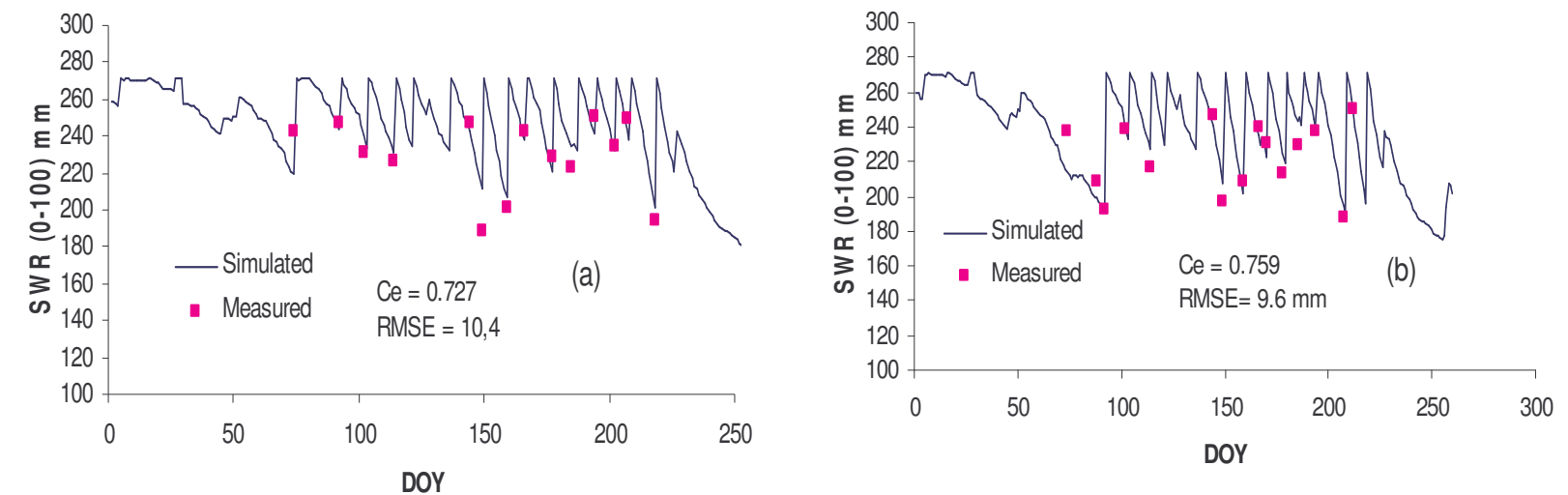

Fig. 7 Soil water reserve (SWR) from 0 to $100 \mathrm{~cm}$ depth for $A_{2}$ (a) and $A_{1}$ (b) plots in 2006) 

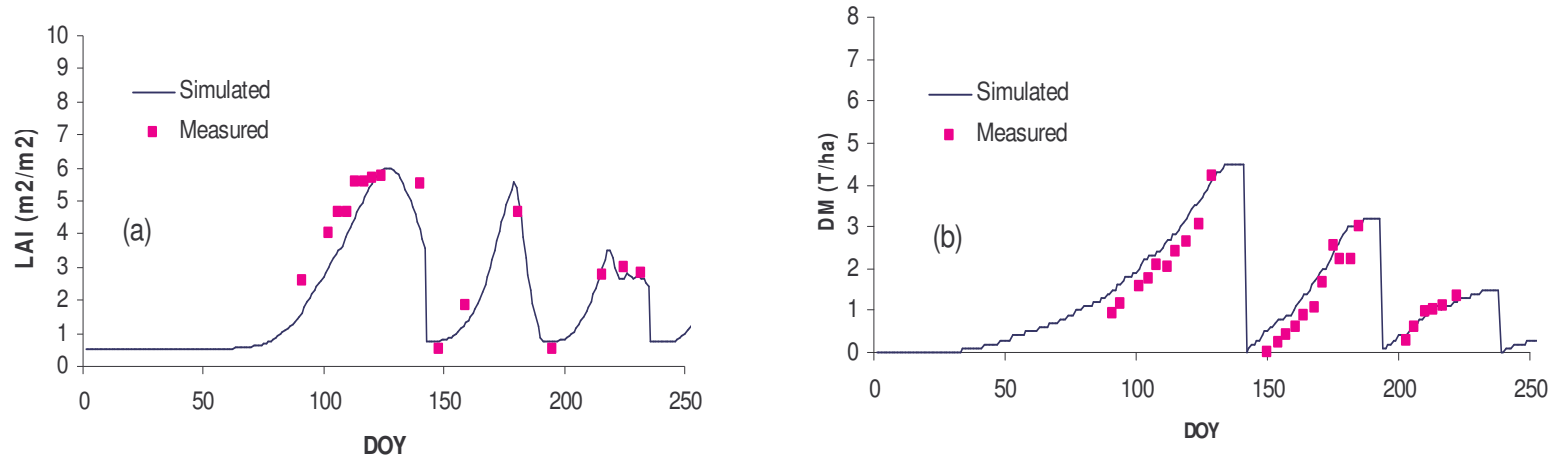

Fig. 8 LAI (a) and DM production (b) for $\mathrm{A}_{1}$ plot in 2005 

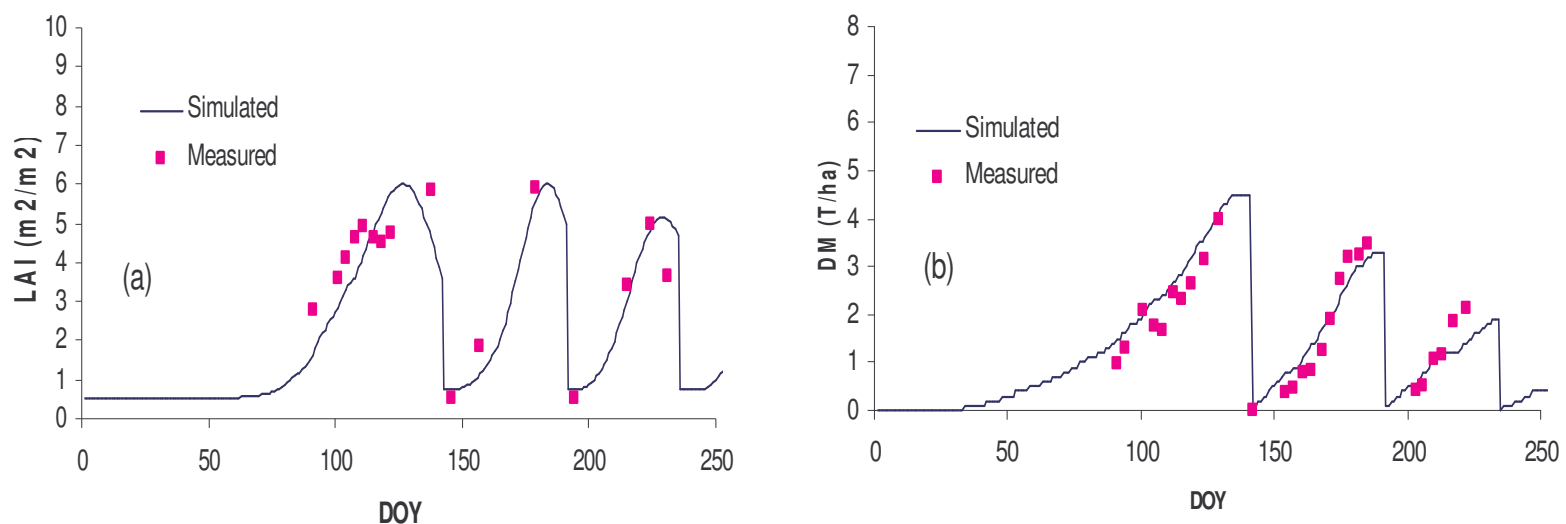

Fig. 9 LAI (a) and DM production (b) for $\mathrm{A}_{2}$ plot in 2005 

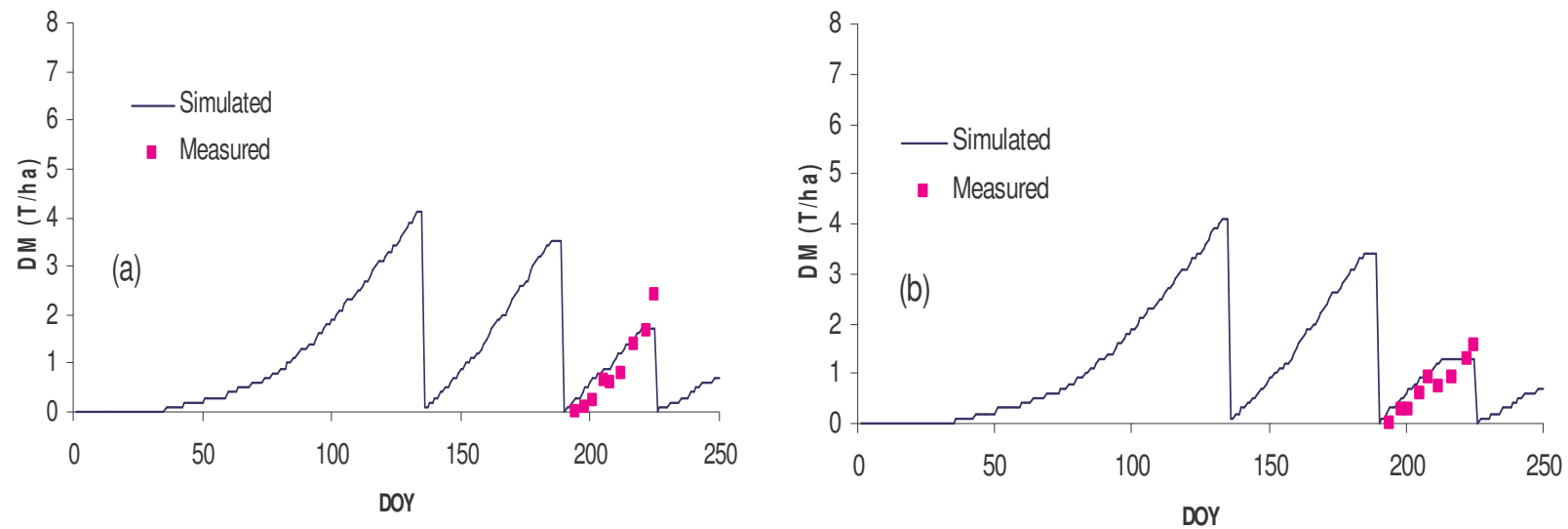

Fig.10 DM production for $\mathrm{A}_{1}$ (a) and $\mathrm{A}_{2}$ (b) plots in 2004 
Original version at Springer site -

http://www.springerlink.com/

DOI 10.1007/s00271-007-0099-3

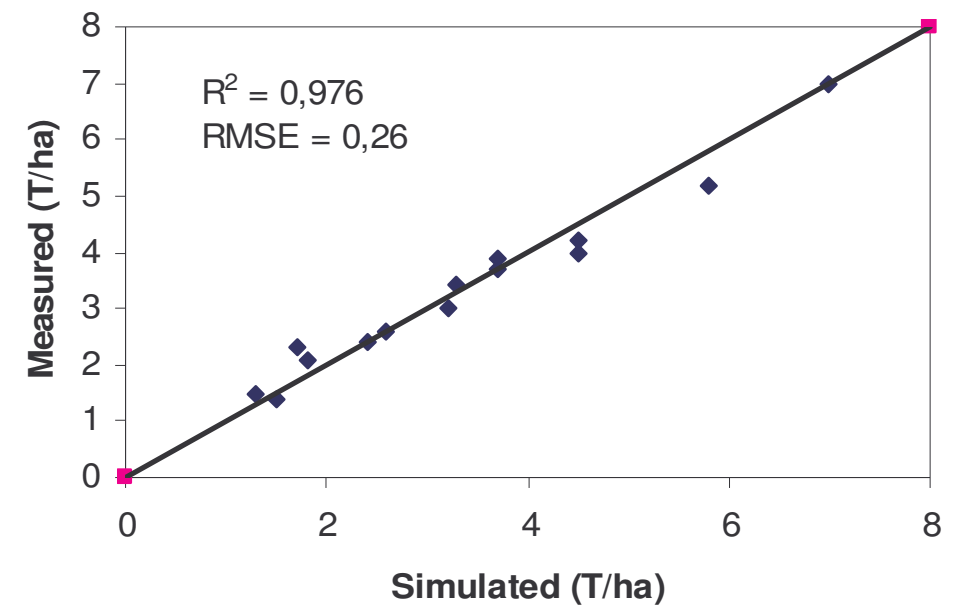

Fig. 11 DM production (manual harvesting) along the 2004-2006 seasons 